\title{
A modo de praxis filosófica.La solidaridad entre el hacernos las paces y la creatividad como preámbulo de las paces creativas
}

\section{As a Philosophical praxis.The Solidarity between Making Peace and Creativity as a Preamble to Creative Peace(s)}

\author{
Sonia París Albert ${ }^{1}$ \\ ORCID: https://orcid.org/0000-0003-1326-5078 \\ Universitat Jaume I (España)
}

Recibido: 30-04-2021

Aceptado: 30-08-2021

\section{Resumen}

La creatividad es una pieza fundamental para hacernos las paces. Tanto es así que el texto resalta la importancia de motivar para atrevernos a arriesgar en lo que a la construcción de la paz y la transformación pacífica de los conflictos se refiere. Con este objetivo, incide en un giro pedagógico que ha de tender hacia una educación creativa en la creatividad y favorecer, al mismo tiempo, el cultivo

1 (sparis@uji.es). Doctora por la Universitat Jaume I (Castellón, España) y Profesora Contratada Doctora en el área de Filosofía del Departamento de Filosofía y Sociología de la misma universidad. Actualmente, es Directora de la Cátedra Unesco de Filosofía para la Paz y coordinadora del Máster Universitario en Estudios Internacionales de Paz, Conflictos y Desarrollo de la UJI. En su perfil docente destaca la impartición de asignaturas como Filosofía Antigua y Medieval, Filosofía Moderna y Contemporánea, Filosofía de la Paz y de la Cooperación Intercultural. A nivel de Máster imparte la asignatura Introducción a los Estudios de Paz y Conflictos. Ha hecho trabajos de investigación en la Universidad de San Francisco (California, EEUU) y ha impartido docencia de postgrado en la Universidad Autónoma del Estado de México (Toluca). Sus principales líneas de investigación son la Filosofía para la Paz y la Transformación Pacífica de los Conflictos, la Filosofía con niñas y niños y la Creatividad. Entre sus últimas publicaciones, se destacan: París Albert, S.: "Filosofía para hacer las paces con niñas y niños. Un estímulo para la creatividad", Convergencia. Revista de Ciencias Sociales, 75 (2017) 65-85. París Albert, S.: "El reconocimiento recíproco en la filosofía de Axel Honneth: contribuciones a la transformación pacífica de los conflictos", Pensamiento. Revista de investigación e información filosófica, 74, 280 (2018) 369-385. París Albert, S.: "Acciones educativas para afrontar algunos desafíos de la filosofía en el siglo XXI", Daimon. Revista Internacional de Filosofia, Murcia, 74 (2018) 105-119. 
de las competencias pacíficas que son favorables al establecimiento de las paces creativas desde las acciones más sencillas y cotidianas. Unas paces creativas que, como epílogo de la solidaridad entre la paz y la creatividad, seguirán los presupuestos de la Filosofía para hacer las paces a modo de praxis filosófica.

Palabras-clave: creatividad, Filosofía para hacer las paces, educación formal, imaginación, paces creativas.

\begin{abstract}
Creativity is an essential piece to make peace. So much so that this text highlights the importance of motivating to be able to take the risk in that what refers to the peacebuilding and the peaceful conflict transformation. With this objective, this paper mentions a pedagogical turn, which has to tend towards a creative education in creativity and facilitate, at the same time, the cultivation of those peaceful competences, which are favourable to the establishment of creative peace $(s)$ from both simple and diary actions. Creative peace(s) that, as the epilogue of the solidarity between peace and creativity, will be down the principles of the Philosophy for making peace as a philosophical praxis.
\end{abstract}

Keywords: creativity, Philosophy for making peace(s), formal education, imagination, creative peace(s).

\title{
Introducción ${ }^{2}$
}

Estas páginas tratan sobre la creatividad en diálogo con la paz a modo de praxis filosófica, con la que se quiere hacer hincapié en la importancia del ser, pensar y actuar creativo para la construcción de culturas de paz y para la transformación pacífica de los conflictos.

La solidaridad entre el hacernos las paces y la creatividad se aborda en este texto bajo la influencia, especialmente, de la propuesta de la Filosofía para hacer las paces de Vicent Martínez Guzmán (Comins Mingol y París Albert 2019; Martínez Guzmán 2001; 2005;), con la que se presta atención a la reconstrucción de las capacidades pacíficas que las personas tenemos para hacernos las paces, así como para transformar el sufrimiento humano y de la naturaleza por medios pacíficos. Con este fin, Vicent Martínez Guzmán (2001; 2005; Martínez Guzmán y otros 2009) diseñó lo que vino a conocer como el Giro Epistemológico de la Filosofía para hacer las paces, el cual cuestiona la supremacía que siempre ha habido de unos saberes sobre otros, como, por

\footnotetext{
${ }^{2}$ Este artículo se vincula con el proyecto financiado por la Generalitat Valenciana (AICO/2020/327) "La agenda de igualdad. Resistencia, retos y respuestas". 
ejemplo, del saber de los hombres sobre el de las mujeres, de Occidente sobre Oriente, de una única forma, además muy concreta, de entender la ciencia, basada en la objetividad y en la neutralidad, de las dicotomías hecho-valor, razón-sentimiento, etc. Frente a estos rasgos, el Giro Epistemológico reivindica el papel de los saberes que han sido marginados, de la interculturalidad, la perspectiva de género, la razón sentimental y el cuidado del medio ambiente, siempre desde un posicionamiento activo, que ensalza la intersubjetividad, el paradigma de la comunicación y la inclusión de los valores, con la pretensión de ir más allá de la simple unilateralización de la racionalidad más pura. Se trata, pues, de un conjunto de principios, aquellos en los que se basa la Filosofía para hacer las paces, que llevan a concluir que la construcción de culturas de paz es posible, siendo ésta una tarea que es responsabilidad de toda la ciudadanía, no solo de los y las grandes dirigentes.

Bajo los presupuestos del Giro Epistemológico, la Filosofía para hacer las paces pasa a ser la praxis filosófica que fundamenta la forma cómo se aborda la relación entre la paz y la creatividad en este artículo. Una relación, la del hacernos las paces con la creatividad, que es el preámbulo de lo que, en el último apartado, vendrán a conocerse como las paces creativas (París Albert 2018a). Así, para llegar a la formulación de estas paces creativas, el texto se estructura en tres apartados. La primera sección aborda la creatividad para la construcción de la paz y la transformación pacífica de los conflictos con el objetivo de ahondar en el sentido del ser, pensar y actuar creativo en este ámbito. El segundo apartado propone la importancia de sentirse motivado para asumir el riesgo de hacer las paces creativamente y, en este sentido, ensalza el papel de una educación creativa en la creatividad. La tercera y última sección nos dirige hacia las paces creativas y sus características, entendidas éstas como el resultado de la solidaridad entre el hacernos las paces y la creatividad.

\section{La inapelable expresión de la creatividad en la Filosofía para hacer las paces}

La esencia de la creatividad ha estado presente en el ámbito de la Peace Research, prácticamente, desde sus inicios, sobre todo, al referirse a los conflictos, respecto a los que siempre se ha defendido la necesidad de su transformación creativa como medio para la construcción y el establecimiento de culturas para hacer las paces. En este sentido, por ejemplo, Johan Galtung (1998; 2003), fundador de la Investigación para la Paz, ha utilizado, en sus textos, la expresión de transformación creativa de conflictos, con la que ha pretendido hacer alusión a la búsqueda de salidas alternativas y pacíficas, gracias 
a las que poder escapar de las habituales formas violentas de conducta a la hora de afrontar la situaciones conflictivas, promoviendo, así, miradas capaces de visibilizar los conflictos desde otros ángulos y propiciando, al mismo tiempo, encuentros comunicativos entre las personas implicadas en una disputa.

Sin embargo y a pesar del uso que se ha hecho del adjetivo "creativo", en realidad, no ha habido un análisis detallado, y en profundidad, sobre la creatividad en los Estudios para la Paz. Ciertamente, esto último, por ejemplo, empezó a leerse, con más detenimiento, de la mano de John Paul Lederach, con quien el alcance de la creatividad en la esfera de los Estudios de los Conflictos ha ganado fuerza gracias a su libro La imaginación moral. El arte y el alma de la construcción de la paz (2007), en cuyas páginas se profundiza en la imaginación moral como competencia posibilitadora del pensamiento creativo para hacer las paces. Idea que, desde el ámbito de la Filosofía para hacer las paces, también, quiso recuperar Vicent Martínez Guzmán cuando elaboró el prólogo del libro de John Paul Lederach arriba mencionado. No obstante, ya antes, Vicent Martínez Guzmán había señalado la importancia de fomentar la imaginación para hacer las paces, muy especialmente, en su libro Podemos hacer las paces. Reflexiones éticas tras el 11-S y el 11-M (2005), en el que se incluyen algunos cuentos como herramienta metodológica para el cultivo de la imaginación en la educación para la paz. De igual manera, Vicent Martínez Guzmán lo hace en algún otro texto posterior en el que, también, propone educar la imaginación y la creatividad en relación con el hacer "poiético" (Martínez Guzmán 2018). Así mismo, hoy en día, también desde la Filosofía, Dora Elvira García González (2014) resalta el valor de la imaginación, poniendo el énfasis, en su caso, en la imaginación ética como una herramienta auxiliar de la razón en el trabajo por la paz, la cual, dice que, al ser "un recurso rico, pleno y humano" (21), hace que la razón, enraizada en su propia realidad, sea "más abierta e incluyente" (21), convirtiéndose, de esta manera, en "condición de posibilidad de la creatividad misma" (22) en todas las esferas de la vida y, por supuesto, también, en aquellos escenarios repletos de conflictos violentos. Esta es la interpretación que lleva a Dora Elvira García González a afirmar que, "estamos obligados a ser buscadores de paz y encontrar rumbos hacia los cuales ir, repensando la realidad frente a nosotros para indagar alternativas posibles desde una imaginación de carácter ético" (García González 2014: 4), la cual nos hará replantear los "supuestos y reposicionarlos intentando sortearlos y emplazar a la paz -como objetivo a lograr- como un nuevo escenario susceptible de convertirse en realidad" (García González 2014: 8; París Albert 2017: 79-80).

Como se puede observar, diferentes son los estudios, por lo tanto, que se refieren a la imaginación y a la creatividad. Sin embargo, la pregunta en la que aquí se quiere indagar, a modo de praxis filosófica, es la siguiente: ¿Qué es ser creativo cuando la creatividad se pone en diálogo con la construcción de la paz 
y la transformación pacífica de conflictos? Para responder a esta pregunta, cabe empezar haciendo alusión al concepto desde el que la creatividad se pretende abordar en estas páginas, el cual, muy influenciado por el campo de estudio de la Filosofía con niñas y niños, expresa la creatividad como la capacidad humana que necesita captar fuentes de la experiencia (Sátiro 2002: 147) para generar más, nuevas y mejores ideas (Sátiro 2011: 136). Entonces, de acuerdo con esta interpretación y en relación con la paz y los conflictos, diremos que la creatividad es la aptitud que, caracterizada por la flexibilidad, originalidad, fluidez y elaboración (Sátiro 2005: 47), hace posible idear múltiples maneras de actuar, siempre en contacto con el contexto social, ofreciendo salidas tan insólitas e inéditas como renovadas y acordes con los tiempos actuales y con las necesidades de cada persona. En este sentido y a diferencia de lo que, habitualmente, se ha creído, es una capacidad, procesadora de la experiencia, presente en todos los sujetos (Rojas Chávez 2015: 187), aunque, evidentemente, en cada individuo pueda llegar a adquirir un grado distinto de desarrollo, de tal modo que encontraremos personas más o menos creativas, pero no sin creatividad. Esta es la percepción que ha llevado, por ejemplo, a Angélica Sátiro (Rojas Chávez 2015: 187) a afirmar que "el hecho que existan genios no significa que los demás no sean creativos", más aún, si tenemos en cuenta que todos los sujetos sienten, de alguna manera, curiosidad, admiración e interés por cómo son y cómo funcionan las cosas que les rodean. De este modo es como, desde la Filosofía para hacer las paces, podemos llegar a decir que la creatividad en la construcción de la paz y en la transformación pacífica de los conflictos, supone imaginar y fantasear para llegar a actuar de una forma inusitada y original (Sátiro 2009: 98), al buscar salidas pacíficas frente a la violencia, contextualizadas en sus entornos, desde diversos campos (arte, ciencia, tecnología, economía, política...) y con distintos lenguajes (verbal, plástico, musical...). Todo ello, sin olvidar que se trata de una capacidad que no “está reñida con la comunicación y la relación social, sino que, por el contrario, es estimulada por éstas" (Barrena 2007: 35), lo que pone de manifiesto su carácter intersubjetivo y muestra, al mismo tiempo, la importancia de las relaciones entre los individuos para ser creativos (Martínez Guzmán 2015; París Albert 2018a). En este sentido, cabe decir que no hay duda de que las personas se estimulan, continuamente, las unas a la otras, por supuesto, también, en lo que a la práctica de la creatividad para la construcción de la paz y la transformación pacífica de los conflictos se refiere.

Por consiguiente, las ideas expuestas más arriba llevan a definir la creatividad como una capacidad que facilita el hecho de ir más allá de lo acostumbrado, superando las propias expectativas y los hábitos en las maneras de ser, pensar y actuar para hacer las paces, cuyo desarrollo se potencia en diálogo con el entorno y con las otras personas. Este es el motivo por el que 
ni que decir tiene que, cuántos mayores sean nuestros encuentros con sujetos creativos, mayor será nuestra creatividad para la transformación pacífica de las injusticias sociales y para la reconstrucción de hábitats de vida saludables y armónicos, propicios al bienestar personal, individual y colectivo.

Como se puede observar, un aspecto que destaca en lo que se viene comentando es la importancia del contacto con el contexto; de ser personas creativas para la paz y la transformación pacífica de los conflictos en función del entorno en el que nos situamos. Con ello, el texto sigue la línea de trabajo de la Filosofía para hacer las paces, en la que se encuentra la gran influencia de obras, como La cultura del conflicto: las diferencias interculturales en la práctica de la violencia (Ross 2005), que describen los conflictos como situaciones culturales, cuyos rasgos definitorios, causas y agentes, entre otros, dependen de su cultura. En esta misma línea, está John Paul Lederach (2007) quien, como se ha señalado anteriormente y a partir de sus estudios de la imaginación sociológica de Charles Wright Mills (1986), defiende el importante rol de la imaginación moral en la transformación pacífica de los conflictos, como una competencia que actúa comprendiendo a las personas en su propio contexto, captando su historia en relación con los otros sujetos y siendo consciente de la gran diversidad humana. En efecto, una concepción de la imaginación moral que muestra sus influencias de la imaginación sociológica de Charles Wright Mills (1986: 25), al percibirse esta última como la cualidad mental que "permite a su poseedor comprender el escenario histórico más amplio en cuanto a su significado para la vida interior y para la trayectoria exterior de la diversidad de individuos"; esto es, como la cualidad que ayuda "a usar la información y a desarrollar la razón para conseguir recapitulaciones lúcidas de lo que ocurre en el mundo" (Wright Mills 1986: 25). De ahí que John Paul Lederach defina la imaginación moral como:

la capacidad de imaginar algo anclado en los retos del mundo real pero a la vez capaz de dar a luz aquello que aún no existe. En referencia a la construcción de la paz, ésa es la capacidad de imaginar y generar respuestas e iniciativas constructivas que, estando enraizadas en los retos cotidianos de la violencia, trasciendan y en última instancia rompan los amarres de esos patrones y ciclos destructivos (Lederach 2007: 63-64).

De la cita anterior se extrae, claramente, que la creatividad, en la construcción y establecimiento de la paz, no olvida las realidades sociales, por muy violentas que éstas sean, sino que, más bien, parte de ellas, del entorno presente, recuperando el pasado, pero enfocándose hacia el futuro, alzándolo con más, nuevas y mejores ideas para la transformación pacífica de los conflictos violentos que en esos contextos tienen lugar. Por ello, la práctica de la creatividad no depende sólo de la aptitud y predisposición creativa de cada 
persona, sino, también, del campo, que hace referencia a los "objetos, reglas, representaciones y notaciones" (Pascale 2005: 69) de una cultura, y del ámbito, que alude al aspecto social que incluye a todos los individuos (70). En este sentido, la creatividad para la construcción de la paz y la transformación pacífica de los conflictos, no debe expresarse como "un tipo de actividad mental, una intuición que tiene lugar dentro de las cabezas de algunas personas especiales" (Csikszentmihalyi 1998: 41), sino como un "fenómeno sistémico" (41), según el que es "el resultado de la interacción de un sistema compuesto por tres elementos: una cultura que contiene reglas simbólicas, una persona que aporta novedad al campo simbólico y un ámbito de expertos que reconocen y validan la innovación" (21). Se tratará, pues, de un proceso a raíz del que un sujeto aporta salidas plurales, insólitas e inesperadas para afrontar los conflictos, las cuales, por muy extrañas que parezcan, resultan óptimas para la transformación de las violencias en una cultura, siendo, además, aceptadas, reconocidas y adoptadas en el ámbito de la Peace Research. Vista así, la creatividad para hacer las paces consiste en un proceso que trae "a la experiencia algo verdaderamente nuevo que es lo suficientemente valorado como para ser agregado a la cultura" (Csikszentmihalyi 1998: 43), identificándose ese "algo" con una idea, acto y/o producto pacífico capaz de cambiar el campo ya existente, al ser acogido por el ámbito de la Investigación para la Paz. Por lo tanto, para que la creatividad genere un producto creativo para hacer las paces, debe ser impulsada por una persona creativa, en un ambiente creativo y de acuerdo con un proceso creativo, resaltándose, de este modo, los cuatro elementos con los que, por ejemplo, Angélica Sátiro (2002), a través de su lectura de la obra de Mihaly Csikszentmihalyi, nos descubre la creatividad.

El concepto de la creatividad, en los términos que se viene manifestando en estas páginas, nos impide no abordar la imaginación como competencia que la posibilita, más aún, al considerar que la creatividad no puede tener lugar sin ella (París Albert 2018b). Se concibe, entonces, la imaginación como la herramienta que nos hace mucho más libres (Ricoeur 2003: 74) para actuar de tantas maneras como nuestra fantasía hace posible, permitiéndonos entender mucho mejor el presente y ampliando, por consiguiente, nuestros horizontes (Domingo Moratalla 2019) desde una perspectiva crítica, reflexiva, comprometida y abierta al cuestionamiento. Así, "el acto de imaginar [...] es un acto mágico" (Sartre 1979: 239) porque, aunque está guiado desde la ficción (Ricoeur 2003: 22), nos acerca a la realidad, tomando posesión de ella, para reescribir (Domingo Moratalla 2001: 297) sus diferentes versiones, después de haber explorado otras maneras de evaluar tanto los hechos como a las personas que nos rodean y a nosotros mismos (297-298). En este sentido, según John Dewey, se convierte en la "puerta de entrada" "a través de la que los significados derivados de experiencias pasadas llegan hasta el presente" 
(Greene 2005: 39), al tiempo que nos hace ser más empáticos y reconocer otras formas de vida (Domingo Moratalla 2019). De hecho, esta última cuestión es fundamental en la construcción de la paz y la transformación pacífica de los conflictos.

De acuerdo con las ideas que se vienen señalando, no cabe duda del importante papel que juega la imaginación en la acción en general y, también, en el proceder creativo. Necesitamos adentrarnos en el mundo de la fantasía para ser capaces de idear maneras de actuar que vayan más allá de nuestras habituales formas de conducta, por muy ilusorias que sean. Más que nunca, esta actitud es la que debe guiar nuestro proceder en las sociedades actuales, en las que parece que el mundo está perdiendo todo su sentido (Domingo Moratalla 2001: 301) a causa, muy especialmente, de la desvalorización y deshumanización constante en todos los ámbitos. Esta es una de las propuestas que quiere hacer la práctica de la Filosofía para hacer las paces, al poner en relación la paz con la creatividad. Tanto es así que considera que si tomamos como referencia la idea según la que, "[...] el simple hecho de que imaginemos que las cosas sean de otro modo puede ser el primer paso para que actuemos guiados por la creencia de que pueden cambiarse" (Greene 2005: 42), ni que decir habrá que la construcción de la paz y la transformación pacífica de los conflictos requerirá, también, tomar el riesgo de atrevernos a ser creativos para afrontar, con sencillez y desde nuestra cotidianidad, los retos del siglo XXI, siempre con miras al establecimiento de culturas para hacer las paces.

\section{Asumir el riesgo de la creatividad al hacer las paces: un giro pedagógico para motivar el ser, pensar y hacer creativo}

Como praxis filosófica, la Filosofía para hacer las paces afirma que la actitud de ser personas atrevidas para correr el riesgo de escapar de lo que es habitual, de lo preestablecido, es fundamental en el trabajo de la creatividad para hacer las paces. De hecho, es, justamente, la voluntad de arriesgar uno de los cuatro elementos que John Paul Lederach (2007) resalta como semilla de la imaginación moral, cuando la sitúa de la mano de la curiosidad paradójica, la centralidad de las relaciones y el acto creativo. Tanto es así que, para John Paul Lederach, la imaginación moral ve la luz con personas curiosas, quienes desean saber, cuánto más mejor, de las relaciones entre las partes en conflicto, incluso, desde un punto de vista paradójico, según el que no buscan situarse sólo en su posición, sino, también, percibir la situación conflictiva desde el lugar de las otras y otros, poniéndose en sus zapatos e intentando sentir lo que ellas y ellos sienten. Con esta actitud, al disponer de la información que las diferentes perspectivas aportan, se facilita el ser, pensar y actuar creativo en 
la transformación pacífica de los conflictos, así como crecen las oportunidades para imaginar salidas improvisadas que, intuidas desde los mismos escenarios de violencia, sirven, por su sencillez y espontaneidad, a la construcción y establecimiento de la paz (París Albert 2019). En este sentido, cuando John Paul Lederach (2007) habla de la imaginación moral, se refiera a ella como esa chispa inesperada que nos ilumina; que tiene lugar cuando nuestros esfuerzos están yendo por otros caminos. Una chispa que relaciona con la serendipia de la imaginación, con la que sigue poniendo de manifiesto cómo el ser, pensar y actuar creativo para hacer las paces lleva a desbordar nuestra imaginación para proponer acuerdos, incluso a veces, por chiripa, esto es, por pura casualidad, más aún, si se tiene en cuenta que, para John Paul Lederach (2007), la serendipia de la imaginación se caracteriza por: la capacidad de visualizar más allá de lo que hay incluso a la vista, la facultad de crear percepciones nuevas que cambian la interpretación de las cosas, y la cualidad de trascendencia que permite trascender realidades y desarrollar actos creativos (61).

La propuesta, que hacemos desde el ámbito de estudio de la Filosofía para hacer las paces, al poner encima de la mesa la solidaridad entre la paz y la creatividad, es, entonces, tener la suficiente motivación como para correr el riesgo de dejarse llevar por la serendipia de la imaginación; como para atreverse con la creatividad, asumiendo esas chispas que, de modo accidental, nos invaden cuando menos lo esperamos, haciéndonos actuar de maneras insólitas, al plantear salidas sencillas, cotidianas e inusuales para hacer las paces.

En el párrafo anterior asoma otra idea que, junto con la voluntad de arriesgar, es fundamental, también, para el devenir de la creatividad en la construcción de la paz. Me refiero aquí a la motivación. No cabe duda de que, para estar motivadas, las personas necesitamos sentir que hacemos algo que nos gusta; algo por lo que, aunque nos suponga algún tipo de obligación, tenemos cierta pasión. De hecho, Ken Robinson (2009: 44) afirma que, para todos los sujetos, es básico estar en "contacto con algo fundamental para su sentido de la identidad, sus objetivos y su bienestar" porque, sólo así, pueden llegar a reconocer "quiénes son realmente y qué deben hacer con su vida" (44). Una idea que Ken Robinson (2009) expresa cuando propone la noción de "el elemento", justamente, para referir, ese algo que tanto nos entusiasma; que tan poco nos molesta hacer; con el que el tiempo parece pasar mucho más deprisa. Se trata, por consiguiente, de una concepción que, aplicada a la creatividad para hacer las paces, supondrá resaltar que las personas tenemos que estar motivadas si lo que buscamos es idear alternativas pacíficas con las que afrontar las violencias actuales, pero no porque dicha motivación nos venga impuesta, sino, más bien, porque, creemos, firmemente, en la realidad del actuar pacífico, y nos sentimos tan atraídas por él, que no podemos dejar de indagar formas para ponerlo en práctica (París Albert 2018a). Se observa, aquí, cómo la 
motivación para hacer las paces se entrelaza con una de las afirmaciones que Vicent Martínez Guzmán (2001; 2005) hizo en el marco de su propuesta de Filosofía para hacer las paces, según la que las y los pacifistas somos las y los realistas porque, aunque sabemos de la presencia de la violencia, seguimos estando motivadas para visibilizar que otras maneras pacíficas de hacernos las cosas son posibles, siendo, por consiguiente, nuestra responsabilidad cómo decidamos hacérnoslas. El reto, para la praxis filosófica de la Filosofía para hacer las paces, está, entonces, en trabajar la motivación para correr el riesgo de ser personas creativas en lo que a la construcción de la paz y la transformación pacífica de los conflictos atañe, así como educar creativamente en la creatividad (París Albert 2018a). Para ello, el papel de la educación, a todos los niveles, pero, sobre todo, en la esfera de la educación formal, es trascendental, por lo que instará a hacer un giro pedagógico a raíz del que las metodologías docentes sean más creativas, la práctica de la creatividad tenga un mayor impulso en las aulas y la sensibilización en valores de paz goce, también, de una mayor presencia en el currículum (París Albert 2017; 2018c).

Se señalaba, en el párrafo anterior, que la motivación para asumir el riesgo de la creatividad en la construcción de la paz y la transformación pacífica de los conflictos no debe venir impuesta por otros agentes ni depender de presiones externas porque, en caso de que así sea, dicha motivación no resultará tanto de nuestra voluntad como de lo que conseguiremos. Justamente, este es el sentido con el que Teresa Amabile (2000) trabaja la motivación en relación con la creatividad, al plantear el Principio de la creatividad por motivación intrínseca, de acuerdo con el que "las personas alcanzarán su máximo grado de creatividad cuando se sientan motivadas fundamentalmente por el interés, satisfacción y reto del trabajo en sí y no por presiones externas" (8). Un principio que, por lo tanto, lleva a diferenciar entre una motivación intrínseca, que será la que proviene del interior de las personas, y otra extrínseca, que procede del exterior (Amabile 1997: 44; 2000: 6). Así, mientras que la primera es favorable al devenir de la creatividad, al ser la que motiva a la persona a trabajar sobre una cuestión que le parece interesante, fascinante y excitante, llegándose a convertir esta cuestión en un reto personal para ella (Amabile 1997: 39), la segunda es menos propicia, ya que se centra, muy especialmente, en el objetivo a lograr y no tanto en el placer que el hecho de hacer una cosa produce (Amabile 2000: 30). Evidentemente, ni que decir tiene que, cuando nos referimos a la construcción de la paz y a la transformación de los conflictos por medios pacíficos es importante el fin en sí mismo, si este se refiere a la creación de sociedades más pacíficas. Sin embargo, a lo que se alude al hablar de la motivación es a la voluntad de hacer las paces, tomando el riesgo de ser creativos porque nosotras y nosotros queremos; porque creemos que es posible; porque disfrutamos haciéndolo; no porque recibamos algún tipo de influencia 
externa o porque otros sujetos nos lo pidan. En este sentido, la motivación intrínseca, repleta de pasión e interés (Amabile 2000: 7), pasa a ocupar un rol fundamental en el ser, pensar y actuar creativo para hacer las paces, aunque, para Amabile, la motivación extrínseca no siempre tenga que ser negativa. Por ello, diferencia entre los motivadores extrínsecos no sinérgicos que tendrán un efecto nocivo sobre la creatividad por el control que ejercen en las personas, y los extrínsecos sinérgicos, que incluyen ciertas recompensas y/o feedbacks que pueden llegar a influir positivamente. En este último caso, resalta, por ejemplo, los motivadores extrínsecos informacionales, que dan información adicional para realizar una acción, y los extrínsecos que habilitan para hacer alguna cosa, los cuales incrementan la implicación de una persona en la acción que está realizando (Amabile 1997: 45; París Albert 2018a: 164).

La educación ejercerá un papel trascendental en el cultivo de la motivación para hacer las paces y de la asunción de riesgos para ser creativos en esta labor. Este texto, cuando se referirá a la educación, aunque, evidentemente, tendrá en cuenta los ámbitos de la educación no formal e informal, pondrá el énfasis, muy especialmente, en la esfera de la educación formal, en la que apostará por un giro pedagógico, gracias al que seguir impulsado metodologías docentes creativas, el trabajo en la creatividad y la presencia de temas de paz en el currículum oficial (París Albert 2017; 2018b; 2018c). Y digo seguir impulsando porque es cierto que, cada vez, tienen lugar más pedagogías dialógicas e interactivas en las aulas, aunque no cabe duda de que todavía queda mucho trabajo por hacer si lo que se pretende es llegar a generalizar y extender esta práctica a cuántos más colegios, institutos y universidades mejor (Comins Mingol y París Albert 2017; París Albert 2018d). Así, según la Filosofía para hacer las paces, el objetivo será fomentar pedagogías del entusiasmo, que José Antonio Marina (2010; 2011) define como aquellas en las que,

\footnotetext{
[...] los profesores generan ambientes de comunicación donde los alumnos se sienten acogidos, estimulados para que expresen sus opiniones, emociones y sentimientos, y que éstos se asuman como parte del proceso de aprendizaje, es decir, el profesor debe propiciar una relación con los alumnos en la que se sienten libres para preguntar, para generar opiniones diferentes, estimular la participación, donde todos los alumnos tienen los mismos derechos y no penalizar el error, sino verlo como un componente más del propio aprendizaje (Marina y Marina 2013: 181).
}

Como se observa en esta cita, se trata, entonces, de pedagogías del entusiasmo cuya finalidad es, sobre todo, estimular al estudiantado para ser partícipe de su propio proceso de aprendizaje. De hecho, se percibe, claramente, su ligazón con la pedagogía problematizadora o libertaria, que Paulo Freire (1970) propuso como contraparte de la tradicional pedagogía 
bancaria. Para Paulo Freire, no había duda de que era más que necesario darle un giro al sistema educativo formal, de tal modo que se lograse alcanzar una subversión entre los roles que, tradicionalmente, habían jugado el profesorado y el estudiantado, con el objetivo de que el primero dejase de ser aquel sobre quien siempre recaía la tarea de educar y el segundo quien, continuamente, resultaba educado. Frente a ello, Paulo Freire (1970) creyó que, en el marco de la educación formal, cualquier agente implicado podía tanto educar como ser educado, por lo que ideó una concepción de la pedagogía en la que el profesorado podía aprender del estudiantado al tiempo que enseñaba, así como el estudiantado enseñar mientras se formaba. Una más que evidente subversión de roles que ha llegado a ser el principal aspecto definitorio de la pedagogía problematizadora o libertaria, ya que, por un lado, promueve una ruptura con la imagen del profesorado como autoridad lejana (Bourdieu y Passeron 2001), quien limita su función a monólogos teatrales, gracias a los que hace "comunicados y depósitos que los educandos, meras incidencias, reciben pacientemente, memorizan y repiten" (Freire 1970: 76), y con el perfil de un estudiantado que basa su participación en memorizar, cuánto más fielmente mejor, los mensajes del profesorado. Por otro lado, se trata de una pedagogía que abre un gran abanico de posibilidades, al liberar tanto al profesorado como al estudiantado de la metodología narrativa que ha constreñido, habitualmente, su participación en las aulas. Así, el profesorado se siente libre para plantear actividades interactivas, dialógicas y mucho más creativas, con las que abordar la creatividad y otros contenidos ajenos al currículum oficial, el cual ha estado basado, esencialmente, en "los saberes más académicos y racionales, las materias clásicas del currículum, la super especialización, la división en compartimentos estancos del saber en materias o asignaturas, los métodos más discursivos o verbalistas..." (Dios Díaz 2013: 159). De igual forma, el estudiantado se libera de la exclusiva memorización de contenidos y toma la palabra para colaborar en las actividades, haciendo oír su voz y construyendo el conocimiento, también, desde sus propias experiencias de vida. En efecto, es una pedagogía que se entiende como un desafío, que hace salir tanto al profesorado como al estudiantado de su zona de confort, trabajando de una forma más creativa y educando en la creatividad, no sólo sobre contenidos del currículum tradicional, sino, también, sobre otros, como pueden ser aquellos que refieren a cuestiones de género, medio ambiente, interculturalidad... y que favorecen la sensibilización creativa en la construcción de la paz y la transformación pacífica de conflictos. Por consiguiente, alude a "una educación mucho más global, crítica, emancipadora, no sexista, solidaria, cooperativa, que evite la exclusión, transformadora..." (Dios Díaz 2013: 158-159) y afín a los "cuatro objetivos interactivos que comparten todos los elementos de la Educación para la Cultura de la Paz" (Tuvilla Rayo 2004: 404), que son 
preparar para la noviolencia, responsabilidad de los ciudadanos del mundo, igualdad de actitudes e investigación crítica de alternativas (París Albert, 2017: 73-74; Tuvilla Rayo 2004: 404-405).

El ser, pensar y actuar creativo para hacer las paces requiere, por consiguiente, una pedagogía del entusiasmo, problematizadora y libertaria, que motive para tomar el riesgo de ser creativo en la construcción de la paz y la transformación de los conflictos por medios pacíficos, y en la que tanto el profesorado como el estudiantado se perciban como investigadores críticos y exploradores creativos. Con esta finalidad, por ejemplo, Martha Nussbaum destaca la imaginación literaria como medio y aboga por su, cada vez, mayor incorporación en las aulas, así como por sus contribuciones a la vida pública (Nussbaum 1997). Para Nussbaum (Argüello Guzmán 2018), la imaginación literaria tiene un rol ético, ya que, a través de la lectura de las novelas, podemos reinterpretar el mundo, poniéndonos en la piel de sus personajes, reconociendo sus anhelos e ilusiones, imaginándonos cómo seríamos nosotras y nosotros si estuviésemos en su lugar, situándonos en otras culturas y aprendiendo otros valores y formas de vida. Estos son los motivos por los que defiende su utilidad en el ámbito de la educación formal, al hacer posible abordar los grandes problemas de la humanidad desde múltiples perspectivas (Nussbaum 1995). $\mathrm{Ni}$ que decir tiene, entonces, que es una excelente herramienta para motivar la imaginación y la creatividad en el hacernos las paces. Unas paces creativas que contribuirán, positivamente, al bienestar natural y humano y que, sin duda alguna, serán el epílogo de la solidaridad entre la paz y la creatividad.

\section{Hacia las paces creativas: el desafío de cultivar nuestras competencias pacíficas con creatividad}

Al cerrar el apartado anterior, se ha incluido el término de paces creativas para hacer referencia, justamente, a esas paces que se construyen con creatividad, tras buscar alternativas que llevan a transformar los conflictos escapando de lo habitual y que hacen posible reconocer la multitud de maneras con las que las personas podemos hacernos las cosas (París Albert 2018a). Se trata, por lo tanto, de paces creativas que, en el marco de la Filosofía para hacer las paces como praxis filosófica, asumen la complejidad humana, así como, también, la pluralidad de ideas en la concepción de la paz, siempre en función de la diversidad de lugares que conforman el mundo. Unas paces creativas que, entonces, sin lugar a dudas se convierten en todo un desafío para las sociedades del siglo XXI, las cuales reivindican, cada vez más, una ciudadanía creativa, capaz "de inventar, de imaginar, de realizar algo nuevo u original" (Barrena 2007: 28) con el objetivo de crear otros mundos posibles 
(Sátiro 2009), en los que el hábito sea el actuar pacífico y creativo a través, por ejemplo, de la transformación de conflictos, del reconocimiento a la diversidad, de la educación inclusiva, del cuidado al medio ambiente, etc. Así, ni que decir tiene que, como se ha venido señalando en estas páginas, afrontar el desafío de las paces creativas, requiere esa voluntad de arriesgarse para ser personas motivadas hacia la construcción creativa de la paz, para lo que la educación, sobre todo, formal, juega un papel esencial, principalmente, si se tiene en cuenta que la constitución de las paces creativas fundamenta su práctica en la reconstrucción de ciertas capacidades pacíficas, que se pueden resumir del siguiente modo (París Albert 2018a: 174):

1. La capacidad para comunicarnos creativamente, considerando a todas las partes en términos de igualdad y dando el mismo valor a todas las voces implicadas en el diálogo, para que todas las personas tengan la oportunidad de expresarse y de ser escuchadas de manera empática, sin juicios previos y desde una perspectiva comprensiva, ética, crítica y creativa (Cortina 1985; 2007; Habermas 1985; 2000).

2. La capacidad para reconocernos mutuamente en nuestra integridad física como sujetos con igualdad de derechos y deberes, que podemos tener distintas formas de ver y entender la vida. Se trata de reconocernos unas personas a las otras asumiendo nuestras diferencias, comprendiéndolas y dándoles valor desde una postura creativa (Honneth 1997; París Albert 2018e).

3. La capacidad para buscar acuerdos creativos basados en la cooperación, a través de los que se pueda ir más allá del simple querer ganar y se puedan adoptar otros posicionamientos más complejos, que lleven a esforzarse para intentar encontrar salidas igual de beneficiosas para todas las personas, superando así la perspectiva más individualista para situarse en otra mucho más colaborativa (Rapoport 1992).

4. La capacidad para percibir las cosas desde distintos puntos de vista y con creatividad, obviando los estereotipos, restando fuerza a nuestros puntos de vista para sumársela a los de las otras personas, y tratando de indagar otras maneras de hacer las cosas que hagan posible la comprensión de la complejidad humana y de la diversidad de lugares que hay en el mundo (Fisher y otros 1999).

5. La capacidad para ejercer nuestros poderes de una manera integrativa y creativa, que evite la jerarquización humana y la subordinación de unas personas bajo el dominio de otras. Poderes que faciliten la concertación de acuerdos y que sean muy conscientes de la fragilidad y de la vulnerabilidad humana (Arendt 1993; Boulding 1993).

6. La capacidad para responsabilizarnos de nuestras acciones y 
de nuestras palabras y de ofrecer respuestas creativas para afrontar sus consecuencias (Austin 1971).

7. La capacidad para hacer fluir los sentimientos, sacándolos desde dentro hacia afuera y regulándolos de una manera creativa para no dejarnos llevar por los más propicios a la violencia y sí, en cambio, por aquellos más cercanos a la convivencia en paz (París Albert 2015a).

8. La capacidad para indignarnos con situaciones que afectan desfavorablemente a la vida de otras personas, y para comprometernos en la búsqueda de salidas creativas en favor de su bienestar individual y social, trabajando por reducir al máximo cualquier tipo de injusticia (París Albert 2015b; 2016).

Con el énfasis en estas capacidades pacíficas, se hace referencia, ciertamente, a las competencias de que disponemos las personas para interactuar entre nosotras y con el medio ambiente por medios pacíficos (Martínez Guzmán $2001 ; 2005)$. Es decir, en verdad, se alude a todos esos poderes pacíficos que son parte de nuestra naturaleza humana, pero que, en ocasiones, olvidamos que tenemos, hasta el punto de dejarnos llevar por las actitudes más violentas, las cuales parecen, entonces, ser nuestras únicas potencialidades. Por este mismo motivo, desde la Filosofía para hacer las paces se afirma que lo que tenemos que hacer es reconstruir dichas competencias pacíficas, esto es, sacarlas hacia afuera, no construirlas desde cero, pues, como ya se ha señalado, se trata de poderes que son inherentes al ser humano. En este sentido, no cabe duda de que esta afirmación pone de manifiesto otra de las tesis más famosas de la praxis filosófica ideada por Vicent Martínez Guzmán (2001; 2005), según la cual las personas podemos actuar de forma pacífica y/o violenta porque tenemos capacidades para ello, por lo que disponemos de alternativas para hacernos las cosas de maneras muy diferentes. Una tesis que, de hecho, quita todo su valor a quienes defienden el carácter biológico de la violencia, al tiempo que ensalza las diferentes oportunidades que tenemos las personas de ser tanto violentas como pacíficas en función de cómo decidamos interactuar y relacionarnos (París Albert 2018a: 172-173).

La idea es, por consiguiente, de acuerdo con lo previamente mencionado en estas páginas, estimular nuestra motivación con el fin de arriesgarnos a recuperar nuestras competencias pacíficas para hacernos las paces creativas, las cuales se han de poner en práctica desde el cuidado y tomando en consideración nuestra cotidianidad y las acciones más sencillas (Lederach 2007; París Albert 2018a; 2019). De este modo, serán unas paces creativas que resaltarán la empatía para ponernos en la piel de las otras y los otros, comprendiendo sus intereses y necesidades como si fueran los propios, con el objetivo de ir, incluso, más allá de nuestras propias expectativas. Una postura empática 
que, así mismo, nos hará ser muy cuidadosos con las maneras con las que nos comunicamos, promoviendo una cordial atención a la diversidad humana y un afable reconocimiento intersubjetivo, siempre desde una concienzuda posición cooperativa basada en esmerados poderes productivos. Tal y como se puede observar, una manera de proceder ésta que partirá de nuestras experiencias cotidianas y que, en efecto, no creerá que las paces creativas son cosa sólo de las y los grandes dirigentes, como ya se ha señalado anteriormente, sino, más bien, que se encuentran al abasto de todas las personas, siendo cada una de nosotras las que podemos aportar nuestro granito de arena para su consecución (Martínez Guzmán 2001; 2005; París Albert 2018a; 2019). Por ello, la motivación para asumir el riesgo de hacernos las paces creativas debe partir de la cotidianidad, de nuestro día a día, y debe valorar las acciones más sencillas, comprendiendo dicha sencillez como contraparte de la complejidad (Lederach 2007), lo que viene a significar que, para advertir la complejidad de las acciones, no nos queda otra más que ir a sus esencias, a desglosarlas en todas sus partes posibles, avanzando, así, desde y hacia la sencillez. En este sentido, la prioridad es no creer que la relación entre la sencillez y la complejidad es la de dos polos antagónicos, sino, más bien, pensar que es un proceso que va desde lo complejo a lo sencillo y de lo sencillo a lo complejo (Panikkar 1993: 10). La cuestión es, entonces, dividir cualquier cosa o acción en todas sus partes básicas a fin de captarlas, en primer lugar, individualmente y, después, en su conjunto, sin obviar las interrelaciones, incertidumbres y azares que forman un sistema, así como las características emergentes que son distintas a las de sus partes. Esto es, la necesidad está en armonizar la complejidad captándola desde la sencillez (Panikkar 1993: 10; París Albert 2019: 36).

Esta concepción de la sencillez, reivindicada desde lo cotidiano, debe beneficiar la construcción de paces creativas, estando ampliamente motivados para correr el riesgo de hacerlas posibles, siendo, pensando y actuando creativamente en la transformación de los conflictos por medios pacíficos. Además, por influencias de la praxis de la Filosofía para hacer las Paces (Martínez Guzmán 2001; 2005), diremos que son paces creativas que se establecerán desde el paradigma de la intersubjetividad, con el que se alza el valor de las relaciones e interacciones de las personas, así como los tres siguientes rasgos de las paces creativas: a) Son paces intersubjetivas porque fluyen allí donde se relacionan las personas y estimulan su creatividad de acuerdo con sus contextos. b) Son paces performativas porque exigen a las personas pedirse cuentas por las maneras cómo se hacen las cosas. c) Son paces comunicativas porque necesitan del diálogo entre las personas para que éstas se sientan motivadas intrínsecamente y puedan reconstruir sus capacidades pacíficas como medios para hacerse las paces. (París Albert 2018a: 175) Tres características éstas de las paces creativas cuyo fluir abre todo un campo de 
trabajo e investigación en el área de la Filosofía para hacer las Paces a modo de praxis filosófica.

\section{Conclusiones}

La creatividad es un claro desafío de las sociedades del siglo XXI en todos los ámbitos y, muy especialmente, también, en la esfera de la construcción de la paz y de la transformación pacífica de los conflictos. No cabe duda de que hay que hablar de la creatividad, recordarla y educar creativamente en ella si lo que se quiere es disponer de una ciudadanía creativa, capaz de ser, pensar y actuar creativamente, yendo más allá de lo habitual y buscando, libremente, salidas creativas a las situaciones de injusticia social que tienen lugar hoy en día. Tanto es así que, de hecho, en estas páginas se ha querido reivindicar el papel de educación formal para afrontar el desafío de la creatividad. Por este motivo, se ha hecho hincapié en la importancia de disfrutar cada vez de más metodologías creativas en las aulas, gracias a las que se den mayores oportunidades para cambiar las rutinas; para permitir los diálogos sobre contenidos ajenos a los currículums más clásicos, abriendo, con ello, las mentes a nuevas y diferentes alternativas.

Una manera de trabajar la creatividad en la construcción de culturas de paz es, sin duda alguna, la reflexión filosófica. De ahí, la trascendencia que en este texto se ha querido dar a la propuesta de la Filosofía para hacer las paces, la cual se puede poner en diálogo, también, con la escuela de la Filosofía con niñas y niños. Teniendo en cuenta esta relación, ni que decir tiene que sería un auténtico lujo cultivar la creatividad desde las y los más pequeños con la metodología de la Filosofía con niñas y niños en conexión con la Filosofía para hacer las paces. Ciertamente, se trataría de usar la metodología dialógica típica de la Filosofía con niñas y niños, a partir de historias y cuentos, a fin de fomentar el ser, pensar y actuar creativo para hacernos las paces desde las escuelas. En efecto, todo un reto en las sociedades actuales, así como una potente línea de investigación futura que se abre en el ámbito de la Filosofía para hacer las paces a modo de praxis filosófica. Una línea que, claro está, favorecerá nuestra motivación para correr el riesgo de ser personas creativas, al tiempo que mostrará la solidaridad entre la paz y la creatividad como preámbulo de las paces creativas. 


\section{Bibliografía:}

Amabile, T.: "Motivating Creativity in Organizations: on doing what you love and loving what you do", California Management Review, 40, 1 (1997) pp. 39-58.

--------: “Cómo matar la creatividad", en T. Amabile (ed.): Creatividad e innovación, Bilbao, Ediciones Deusto, 2000, pp. 1-31.

Arendt, H.: La condición humana, Barcelona, Paidós, 1993.

Argüello Guzmán, L. A.: "La imaginación narrativa de Martha Nussbaum ante la crítica académica", Question, 1, 60 (2018) pp. 3-16.

Austin, J. L.: Palabras y acciones, Cómo hacer cosas con palabras, Buenos Aires, Paidós, 1971.

Barrena, S.: La razón creativa. Crecimiento y finalidad del ser humano según C. S. Peirce, Madrid, Ediciones Rialp, 2007.

Boulding, K.: Las tres caras del poder, Barcelona, Paidós, 1993.

Bourdieu, P. y Passeron, J. C.: La reproducción. Elementos para una teoría del sistema de enseñanza, Madrid, Editorial Popular, 2001.

Cortina, A.: Razón Comunicativa y responsabilidad solidaria, Salamanca, Ediciones Sígueme, 1985.

-: Ética de la razón cordial. Educar en la ciudadanía, Oviedo, Nobel, 2007.

Comins Mingol, I. y París Albert, S.: "Recognition and Compassion at stake: Towards a Nonkilling Education", en J. Evans Pim y S. Herrero Rico (eds.): Nonkilling education, Honolulu, Center for Global Nonkilling, 2017, pp. 127-141

-: Vicent Martínez Guzmán. Els pacifistes som els realistes. Selecció de textos, Barcelona, Institut Català Internacional per la Pau, 2019.

Csikszentmihalyi, M: Creatividad. El fluir y la psicología del descubrimiento y la invención, Barcelona, Paidós, 1998.

Dios Diz, M.: "El currículum de la noviolencia en la educación para la paz", en I. Comins Mingol y F. A. Muñoz (eds.): Filosofías y praxis de la paz, Barcelona, Icaria, 2013, pp. 141-164.

Domingo Moratalla, T.: "La fenomenología hermenéutica de Paul Ricoeur: mundo de la vida e imaginación", Investigaciones fenomenológicas: Anuario de la Sociedad Española de Fenomenología, 3 (2001) pp. 291302.

"Imaginación hermenéutica y fenomenología", http://www. filosofiayliteratura.org/1/palabras/imaginacion_ricoeur.htm (Fecha de acceso: 29 de julio de 2019).

Fisher, R. y otros: Más allá de Maquiavelo. Herramientas para afrontar conflictos, Barcelona, Granica, 1999. 
Freire, P.: Pedagogía del oprimido, Madrid, Siglo XXI Editores, 1970.

Galtung, J.: Tras la violencia, 3R: reconstrucción, reconciliación, resolución: afrontando los efectos visibles, Bilbao, Bakeaz, 1998.

---------: Paz por medios pacíficos: paz y conflicto, desarrollo y civilización, Bilbao, Bakeaz, 2003.

García González, D. E.: "Hacia una prospectiva de paz a partir del realismo de la violencia: una construcción desde la imaginación ética”, en D. E. García González (coord.): Trascender la violencia. Críticas y propuestas interdisciplinarias para construir la paz, México, Porrúa, 2014, pp. 3-30.

Greene, M.: Liberar la imaginación: ensayos sobre educación, arte y cambio social, Graó, Barcelona, 2005.

Habermas, J.: Conciencia moral y acción comunicativa, Barcelona, Península, 1985. 2000.

Honneth, A.: La lucha por el reconocimiento: por una gramática moral de los conflictos sociales, Barcelona, Crítica, 1997.

Lederach, J. P.: La imaginación moral. El arte y el alma de la construcción de la paz, Bilbao, Bakeaz, 2007.

Marina, J. A.: La educación del talento, Barcelona, Planeta, 2010.

Los secretos de la motivación, Barcelona, Planeta, 2011.

Marina, J. A. y Marina, E.: El aprendizaje de la creatividad, Barcelona, Ariel, 2013.

Martínez Guzmán, V.: Filosofía para hacer las paces, Barcelona, Icaria, 2001.

----------: Podemos hacer las paces. Reflexiones éticas tras el 11-S y el 11-M, Bilbao, Desclee de Brouwer, 2005.

---------: "Intersubjetividad, interculturalidad y política en la Filosofía para la Paz", Thémata. Revista de Filosofía, 52 (2015), pp. 147-158.

: "Educar la imaginación y la creatividad para hacer las paces: el hacer «poiético»", en S. París Albert y S. Herrero Rico (eds.): El quehacer creativo: Un desafio para nuestra cotidianidad, Madrid, Dykinson, 2018, pp. 21-36

Martínez Guzmán, V. y otros: "La nueva agenda de la filosofía para el siglo XXI: los estudios para la paz", Convergencia. Revista de Ciencias Sociales, 16 (2009), pp. 91-114.

Nussbaum, M. C.: "La imaginación literaria en la vida pública”, Isegoría, 11 (1995) pp. 42-80.

--------: Justicia poética. La imaginación literaria y la vida pública, Barcelona, Andrés Bello, 1997.

Panikkar, R.: Elogio de la sencillez. El arquetipo universal del monje. Navarra: Editorial verbo Divino, 1993. 
Pascale, P.: “¿Dónde está la creatividad? Una aproximación al modelo de sistemas de Mihaly Csikszentmihalyi”, Arte, Individuo y Sociedad, 7 (2005) pp. 61-84.

París Albert, S.: "El derecho humano a culturas para la paz renovadas a través de una revalorización de la racionalidad sentimental", RIDH Revista Interdisciplinar de Direitos Humanos, 4 (2015a) pp. 51-65.

-: "Hacia una revalorización de la filosofía en diálogo con la indignación, Convergencia. Revista de Ciencias Sociales", 68 (2015b) pp. 207-229.

---------: "Indignación para la acción: un reencuentro con la filosofía de Friedrich Nietzsche”, en V. J. Benet y Á. Arévalo Salinas (eds.): De víctimas a indignados. Imaginarios del sufrimiento y de la acción política, Valencia, Tirant Humanidades, 2016, pp. 205-218.

-: "Filosofía para hacer las paces con niñas y niños. Un estímulo para la creatividad", Convergencia. Revista de Ciencias Sociales, 75 (2017) pp. 65-85.

: "Hacia una reconstrucción de las paces creativas para la ciudadanía global”, Revista de Paz y Conflictos, 11, 1 (2018a), pp. 159-179.

: "Propuestas educativas para una refundación de la imaginación", en S. París Albert y S. Herrero Rico (eds.): El quehacer creativo: Un desafio para nuestra cotidianidad, Madrid, Dykinson, 2018b, pp. 133-152.

: "Acciones educativas para afrontar algunos desafíos de la filosofía en el siglo XXI", Daimon. Revista Internacional de Filosofía, 74 (2018c) pp. 105-119.

---------: "Putting philosophy to the service of schools to give children's voices real value", Childhood \& Philosophy, 14, 30 (2018d) pp. 453-470.

-- "El reconocimiento recíproco en la filosofía de Axel Honneth: contribuciones a la transformación pacífica de los conflictos", Pensamiento. Revista de investigación e información filosófica, 74, 280 (2018e) pp. 369385

: "Educación para la paz, creatividad atenta y desarrollo sostenible", Revista Internacional de Educación para la Justicia Social, 8, 1 (2019) pp. 2254-3139.

Rapoport, A.: Peace: An idea whose time has come, Ann Arbor, University of Michigan Press, 1992.

Ricoeur, P.: La memoria, la historia, el olvido, Madrid, Trotta, 2003.

Robinson, K.: El elemento, Barcelona, Random House Mondadori, 2009.

Rojas Chávez, V. A.: "Diálogo con Angélica Sátiro", Análisis, 47, 86 (2015) pp. 181-192.

Ross, M. H.: La cultura del conflicto: las diferencias interculturales en la práctica de la violencia, Barcelona, Paidós, 2005.

Sartre, J. P.: La imaginación, Barcelona, Edhasa, 1979. 
Sátiro, A.: “CCrear? Un artículo para dialogar”, en M. Lipman (ed.): Filosofía y Educación, Madrid, Ediciones de la Torre, 2002, pp. 145-161.

: "Cómo el pensamiento vuela cuando jugamos a pensar creativamente...", en VVAA (coords.): Filosofía en la escuela. La práctica de pensar en las aulas, Barcelona, Graó, 2005, pp. 47-53.

----------: "Creatividad social: necesidad de transformar y crear mundos", en A. Sátiro (coord.): Pasión por crear, placer de admirar, necesidad de transformar. Iniciación al arte como herramienta de juego, conocimiento y transformación, MACUF, La Coruña, 2009, pp. 96-115.

: "La creativitat com a motor de desenvolupament i d'inclusió social", Cantabou, 33 (2011) pp. 4-13.

Tuvilla Rayo, J.: “Cultura de paz y Educación”, en B. Molina Rueda y F. Muñoz (eds.): Manual de Paz y Conflictos, Granada, Universidad de Granada, 2004, pp. 387-425.

Wright Mills, C.: La imaginación sociológica, México, Fondo de Cultura Económica, 1986. 
